\title{
Reconstituir famílias e demarcar diferenças: virtualidades da metodologia para o estudo de grupos étnicos ${ }^{*}$
}

\author{
Sergio Odilon Nadalin ${ }^{\star \star}$
}

\begin{abstract}
Este artigo pretende revisitar alguns textos concernentes a um grupo de imigrantes de origem germânica e seus descendentes em Curitiba (Paraná), marcando as virtualidades da metodologia das reconstituições familiares. Seu conteúdo considera uma necessária atitude crítica que pautou o desenvolvimento desses trabalhos, tendo em vista principalmente as limitações da metodologia e das próprias fontes "paroquiais". Os primeiros resultados centraram-se em estudos de fecundidade de três coortes de casamentos (1866-1939) e, na continuidade, desenvolveram-se esforços no sentido de explorar a base de dados com objetivos que extrapolaram a demografia histórica stricto sensu. O quadro teórico da investigação está alicerçado numa história da construção de fronteiras étnicas, tendo como horizonte a imigração européia, a urbanização, questões político-ideológicas e a história de uma instituição religiosa.
\end{abstract}

Palavras-chave: Reconstituição de famílias. Imigração germânica. Contatos culturais. Fronteiras étnicas e etnicidade.

\section{Introdução}

Este artigo tem como objetivo "revisitar", mais uma vez, ${ }^{1}$ vários textos produzidos como resultado de uma atividade de pesquisa centrada em base de dados obtida pelas técnicas de reconstituição de famílias. Pretende-se, em especial, recuperar uma atitude crítica que pautou o desenvolvimento desses trabalhos, considerando-se principalmente alguns limites e virtualidades da metodologia (e, em certo sentido, limites e virtualidades das próprias fontes), respeitando as especificidades de uma investigação.

$\mathrm{Na}$ década de 70 , as recomposições familiares em fichas especiais ${ }^{2}$ - tanto para estudos de demografia retrospectiva (HENRY, 1956; GAUTIER e HENRY, 1958), como para a história demográfica (GOUBERT, 1960) - estavam na moda. Estimulado por Maria Luiza Marćlio, pela minha orientadora durante o Mestrado, Altiva Pilatti Balhana, e pela presença de Louis Henry

\footnotetext{
* O presente artigo resulta de comunicação intitulada A história de grupos étnicos: virtualidade das técnicas de reconstituição de famílias, apresentada no II Congresso da Associação Latino-Americana de População, em Guadalajara, México, 3 a 5 de setembro de 2006.

${ }^{\star}$ Pesquisador bolsista do Conselho Nacional de Desenvolvimento Científico e Tecnológico - CNPq e professor do Departamento de História da Universidade Federal do Paraná - UFPR.

${ }^{1}$ O primeiro ensaio nessa direção resultou numa comunicação apresentada no Seminário de Córdoba (IUSSP), em 1998 (NADALIN, 1998).

2 "Considerando (...) que o indivíduo passa os momentos essenciais de sua vida, isto é, o nascimento, o casamento e a morte diante do cura da sua paróquia ou do cartório de sua cidade, o princípio básico da metodologia consiste no agrupamento em fichas especiais de todas as informações relativas a estes eventos." (NADALIN, 2004, p.116).
} 
em Curitiba, no verão de $1974,{ }^{3}$ propus a este último a construção de uma tese de doutorado inserida nas linhas de pesquisa desenvolvidas no Ined (França). O âmbito acadêmico do projeto estaria coberto pela École des Hautes Études en Sciences Sociales e, com essa finalidade, fez parte da bagagem que me acompanhou em Paris uma coleção de fichas Fleury-Henry de levantamento nominativo abreviado, ${ }^{4}$ contendo informações a respeito dos dados de batismos, casamentos e óbitos dos luteranos em Curitiba, de 1866 a 1969.

Assim, desde aquele momento, tive que construir uma problemática que se diferenciava bastante dos tradicionais estudos de paróquias que se produziam às centenas na época, na maioria das vezes voltados a investigações de populações do Antigo Regime europeu. Problemática essa que se solidificava teórica e metodologicamente, à medida que decidi valorizar o investimento inicial, continuando os procedimentos relativos à reconstituição e acrescentando duas coortes de casais em observação.

Essa escolha implicava um engajamento. ${ }^{5}$ Interessado pelo tema da imigração estrangeira no Brasil, em especial pela presença de imigrantes de origem germânica na Província (depois Estado) do Paraná, investi na ampliação e no aprofundamento de questões colocadas à base de dados assim construídos. ${ }^{6}$ Tratava-se de examinar alguns aspectos do marco teórico delimitado pela história de uma população de origem estrangeira relativamente recente no Brasil (1866-1987), cujo dinamismo em Curitiba tem se mantido com um ritmo singular, embora pautado, de maneira geral, pelos fenômenos relativos à transição demográfica. As questões colocadas adquiriam coloração mais viva ao objetivar uma paróquia evangélica e luterana, congregando imigrantes de origem germânica e seus descendentes inseridos na sociedade curitibana.

\section{Definição do objeto}

O grupo étnico-religioso definia-se naturalmente na longue durée, distinguindo-se na sua história dois grandes períodos. No primeiro, evidente até pelo menos a década de 30 , várias gerações de luteranos sucederam-se conformando uma consciência étnica original, caracterizada pela valorização ideológica do Deutschtum. ${ }^{7} \mathrm{~A}$ coesão do grupo desses imigrantes e descendentes, desde a segunda metade dos oitocentos, foi influenciada pela identificação que dele fazia a sociedade receptora, completando-se o quadro de uma dinâmica de conflito, em grande parte fundamento da "etnicidade".

Assim, esta história deve considerar os ritmos temporais da unidade interna da comunidade, articulando forças comunitárias (centrípetas), com outras de caráter estamental, que jogariam contra a Gemeindschaft, bem como as forças societárias (centrífugas), impostas pelo desenvolvimento das relações sociais numa cidade que se modernizava e cujos habitantes adequavam-se de modo gradativo ao mercado, levando, portanto, à assimilação ou à integração dos elementos do grupo. ${ }^{8} \mathrm{O}$ quadro teórico da investigação está alicerçado ainda numa história da construção de fronteiras étnicas (BARTH, 1998), definidas a partir da continuidade do

\footnotetext{
${ }^{3}$ Dessa presença resultou a publicação do manual Técnicas de análise em Demografia Histórica (Curitiba: Universidade Federal do Paraná, 1977), posteriormente a versão francesa Techniques d'Analyse em Démographie Historique (Paris: PUF/Ined, 1980). Foi desta publicação que se originou o manual português publicado em Lisboa: Gradiva, 1988. Enfim, a experiência curitibana orientou de certa maneira o curso que Louis Henry dava às quartas-feiras de manhã, no Ined, durante o semestre letivo francês.

4 "Dépouillement nominatif abrégé" (FLEURY; HENRY, 1965:71-5).

${ }^{5}$ Desde então sempre apoiada pelo CNPq.

${ }^{6}$ Desde logo, quero aqui manifestar meu regozijo pelo fato de que a problemática muito avançou em função do profícuo diálogo mantido com Alain Bideau, da Universidade de Lyon 2 (França).

${ }^{7}$ Termo que poderia ser traduzido como "germanidade" (SEYFERT, 1981, p.3-4). O conceito também expressava uma síntese das "qualidades nacionais germânicas" (idem, 1994: 17). Finalmente, interessa salientar que, no seu âmbito, está bem expressa a prática de uma Muttersprache (língua mãe) e da religião evangélica luterana, pelo menos até esta época entendida como uma profissão de fé alemã (ver, por exemplo, os argumentos de Hermann Dohms, em Dreher, 1984, p. 115-120).

${ }^{8}$ Dada a tradicional confusão conceitual concernente a estes termos, a referência aqui é Wachtel (1988, p.118-119).
} 
fluxo imigratório europeu, de um processo de urbanização (Curitiba), de questões político-ideológicas (o embate de duas concepções de cidadania, jus sanguinis versus jus solis) e da história de uma instituição religiosa (Igreja Evangélica Luterana do Brasil).

Acompanhando a inserção do grupo na história da sociedade curitibana, foi possível demarcar conjunturas, relativas sincronias detectáveis como resultado de diversos cortes transversais no tempo. Esta periodização é coerente com os recortes que definem as diversas histórias matrimoniais verificadas, respectivamente com início de observação, entre 1866 e 1894, 1895 e 1919, 1920 e 1939, 1940 e $1969 \ldots$ Os primeiros resultados centraram-se em análises de fecundidade de três coortes de casamentos (1866-1939) ${ }^{9}$ e, na continuidade, desenvolveram-se esforços no sentido de explorar a base de dados com objetivos que extrapolaram a demografia histórica stricto sensu, ${ }^{10}$ abordando estudos de família, sexualidade, compadrio e nomes de batismo, passando por uma tentativa relativamente frustrada de informatização proporcionada pelo SYGAP - Système de Gestion et d'Analyse de Population (BIDEAU et al., 1991).

\section{Fecundidade e sexualidade}

Foi verificado que, de um período para outro, diminuiu significativamente o número de filhos entre os casais mais estáveis do grupo, recuperados pelas fichas MF, ${ }^{11}$ fato demonstrado pela variação das taxas de fecundidade legítima e pelos indicadores associados, tais como o declínio da idade da última maternidade (e aumento, de uma coorte para outra, da idade da mulher no início da observação), a redução da descendência completa e um maior intervalo entre o casamento e o primeiro nascimento, bem como entre os filhos sucessivos. ${ }^{12}$ Se forem abstraídas as condições próprias nas quais o fenômeno se desenvolve - e aqui se impõe também a constatação da "modernidade" demográfica do grupo em relação ao conjunto da população brasileira -, é fácil incluir a redução do número de crianças observada entre os luteranos em Curitiba na primeira onda internacional de declínio da fecundidade, ocorrida no período abrangido pelas décadas de 1880 e 1930 (THERBORN, 2006, p. 344). ${ }^{13}$

A gradativa atitude malthusiana desenvolvida pelos casais da comunidade está relacionada à aquisição de uma nova racionalidade, cujas explicações têm sido elaboradas não sem muita dificuldade (THERBORN, 2006, p. 352-353). De qualquer maneira, esses comportamentos também se associam à sexualidade exercida pelos jovens do grupo, o que poderia ser evidenciado pelo estudo dos intervalos entre o casamento e o nascimento do primeiro filho. Foi dessa forma que se observou uma significativa diminuição das concepções pré-nupciais no período de 1866 a 1939 , de praticamente $30 \%$ para $15 \%$ (Tabela 1). ${ }^{14}$

\footnotetext{
${ }^{9}$ As tentativas de estudo da mortalidade esbarraram em problemas metodológicos, principalmente relacionados à qualidade das fontes (NADALIN, 1978, p. 542-555).

${ }^{10}$ Sobre essas questões relacionadas a uma epistemologia da Demografia Histórica, ver Nadalin (2004, p. 71-75).

${ }^{11}$ Ao se reconstituírem famílias, as fichas respectivas classificam-se em "M", abertas a partir do casamento ("Marriage") e em "E", quando a vida do casal é registrada a partir do primeiro filho nascido na paróquia (casamento exterior - "Exterieur"). Cada um destes conjuntos pode ser classificado, por sua vez, em fichas "F" ("Fermé", fechadas) - quando o fim do casal é observado no âmbito da paróquia, documentado por um evento qualquer (geralmente o óbito do cônjuge) - e "O" ("Ouvert", abertas) - quando não se documenta o fim do casal (geralmente em função de algum tipo de emigração). De modo que, em síntese, as fichas de família podem ser classificadas em "MF", "EF", "MO" e "EO".

${ }^{12}$ No jargão da demografia, intervalos proto e intergenésicos (BIDEAU; NADALIN, 1988, p. 1044-1052).

${ }^{13}$ De fato, tendo como instrumento a difusão do conhecimento sobre anticoncepcionais, "as investidas pioneiras dos casais franceses e americanos tornaram-se uma onda internacional quando a eles se juntaram outros europeus ocidentais e colonos europeus do além-mar" (THERBORN, 2006, p. 345). De acordo com o autor em referência, a segunda vaga teria começado bem mais tarde, nas décadas finais do século XX, alcançando os países do Terceiro Mundo, inclusive toda a sociedade brasileira (idem, p.345-7).

${ }^{14}$ Para um estudo mais completo da problemática das concepções pré-nupciais na comunidade e a relação dos números apresentados na tabela em evidência com comportamentos herdados de uma sexualidade "camponesa", ver Nadalin (1997/ 1998).
} 
TABELA 1

Intervalos protogenésicos, independente da idade da mulher ao casar (1) Comunidade Evangélica Luterana de Curitiba - 1866-1939

\begin{tabular}{|c|c|c|c|c|c|c|c|c|c|c|}
\hline \multirow{2}{*}{$\begin{array}{l}\text { Períodos } \\
\text { dos } \\
\text { casa- } \\
\text { mentos }\end{array}$} & \multicolumn{2}{|c|}{$\begin{array}{l}\text { Intervalos } \\
\text { "normais" (2) }\end{array}$} & \multicolumn{2}{|c|}{$\begin{array}{l}\text { Concepções } \\
\text { pré-nupciais (3) }\end{array}$} & \multicolumn{2}{|c|}{$\begin{array}{c}\text { Intervalos } \\
\text { "negativos" (4) }\end{array}$} & \multicolumn{2}{|c|}{$\begin{array}{c}\text { Total } \\
\text { concepções } \\
\text { pré-nupciais (5) }\end{array}$} & \multicolumn{2}{|c|}{$\begin{array}{c}\text { Total } \\
\text { dos nascimentos }\end{array}$} \\
\hline & $\begin{array}{c}N^{\text {Nos }} \\
\text { absolutos }\end{array}$ & $\%$ & $\begin{array}{c}\mathrm{N}^{\text {os }} \\
\text { absolutos }\end{array}$ & $\%$ & $\begin{array}{c}N^{\text {os }} \\
\text { absolutos }\end{array}$ & $\%$ & $\begin{array}{c}N^{\text {os }} \\
\text { absolutos }\end{array}$ & $\%$ & $\begin{array}{c}\mathrm{N}^{\text {os }} \\
\text { absolutos }\end{array}$ & $\%$ \\
\hline $1866-1894$ & 158 & 70,2 & 48 & 21,3 & 19 & 8,5 & 67 & 29,8 & 225 & 100,0 \\
\hline $1895-1919$ & 223 & 82,0 & 32 & 11,8 & 17 & 6,2 & 49 & 18,0 & 272 & 100,0 \\
\hline 1920-1939 & 192 & 85,3 & 18 & 8,0 & 15 & 6,7 & 33 & 14,7 & 225 & 100,0 \\
\hline Total & 573 & 79,4 & 98 & 13,6 & 51 & 7,1 & 149 & 26,0 & 722 & 100,0 \\
\hline
\end{tabular}

Fonte: Comunidade Evangélica Luterana de Curitiba - Registros Paroquiais.

(1) Fichas MF e MO, incluídos os nascimentos reencontrados.

(2) Intervalos protogenésicos iguais ou maiores do que oito meses.

(3) Intervalos protogenésicos de 0 a 7 meses.

(4) Intervalos referentes às crianças que nasceram antes do casamento.

(5) Dados subestimados. Tendo em vista a inclusão no conjunto de nascimentos "reencontrados" (oriundos da recuperação de crianças a partir de registros de casamentos, óbitos e outras fontes de informação), supõe-se que uma determinada parcela de concepções pré-nupciais foi "perdida".

Uma análise preliminar dos dados permite creditá-los à utilização de métodos contraceptivos, fato que poderia ser confirmado pela comparação entre as cifras concernentes e o número de crianças nascidas antes do casamento. Mesmo pouco significativos, os intervalos denominados de "negativos" mostrariam que, na prática e de uma coorte para outra, não houve mudança de comportamento dos casais que viviam consensualmente antes do casamento. Quanto às mudanças entre jovens comprometidos da comunidade, tudo indica que eles deviam namorar, cada vez mais, ao abrigo de algumas precauções.

Na mesma direção, outra evidência fundamenta-se em demonstração possibilitada pelos dados das famílias reconstituídas, comparando-se a fecundidade das mães que tiveram filhos antes das núpcias ou casaram-se grávidas, com a fecundidade daquelas cujo intervalo protogenésico era igual ou maior do que oito meses (Tabela 2). Nas famílias em que foi observado um nascimento antes do casamento ou uma concepção pré-nupcial, para os três períodos analisados, o fato de a fecundidade ser sempre mais elevada para as mulheres ainda no grupo de idades no qual elas se casaram, em relação àquelas da mesma idade cujo matrimônio remonta a um grupo anterior, está relacionado às concepções pré-nupciais (BIDEAU; NADALIN, 1990, p. 140). Ou seja, e com todo o cuidado tendo em vista a pequenez das cifras observadas, os dados sugerem que, independente da descendência final, é um pouco maior a "fertilidade" das jovens que conceberam antes do casamento, quando comparadas ao conjunto de mulheres cujo intervalo entre o casamento e o primeiro nascimento é "normal". ${ }^{15}$

No entanto, as análises realizadas conduziram da mesma forma à possibilidade de se explicar a diminuição da freqüência das concepções pré-matrimoniais em função da problemática dos contatos culturais. A partir da segunda geração da comunidade (1895 em diante), constituída principalmente por filhos de imigrantes (BIDEAU; NADALIN, 1988, p. 1043), constrói-se gradativamente uma nova

\footnotetext{
${ }^{15}$ Já se calcularam as possibilidades de concepção em uma só relação sexual: não é maior do que $2 \%$ a $4 \%$ num casal normal, jovem e saudável. Isto significa que, em média, seria preciso uma convivência sexual marital, ou quase marital - e sem proteção alguma-, de várias semanas ou meses, para possibilitar uma concepção (STONE, 1989, p. 311 - tudo indica que essa informação foi obtida em PICHAT, 1965).
} 
TABELA2

Taxas corrigidas e comparadas de fecundidade (1) - mulheres cujo primeiro filho foi concebido no interior do matrimônio e mulheres " $J$ ", que tiveram filhos ou conceberam antes do casamento (2) Comunidade Evangélica Luterana de Curitiba - 1866-1939

\begin{tabular}{ccccccccccc}
\hline Idade da & Número de & \multicolumn{10}{c}{ Idade observada da mulher } & & Descendência \\
mulher & $\begin{array}{c}\text { fichas de } \\
\text { ao casar }\end{array}$ & $\begin{array}{c}15-19 \\
\text { família }\end{array}$ & $\begin{array}{c}20-24 \\
\text { anos }\end{array}$ & $\begin{array}{c}25-29 \\
\text { anos }\end{array}$ & anos & $\begin{array}{c}30-34 \\
\text { anos }\end{array}$ & $\begin{array}{c}35-39 \\
\text { anos }\end{array}$ & $\begin{array}{c}40-44 \\
\text { anos }\end{array}$ & $\begin{array}{c}45-49 \\
\text { anos }\end{array}$ & \begin{tabular}{c} 
completa \\
\hline
\end{tabular}
\end{tabular}

\section{Mulheres \\ casadas em \\ 1866-1894}

$\begin{array}{lccccccccc}\text { 15-19 anos } & 79 & 443 & 465 & 409 & 315 & 248 & 132 & 015 & 8,763 \\ & 24 \text { "J" } & 704 & 458 & 396 & 289 & 163 & 088 & 014 & 8,332 \\ 20-24 \text { anos } & 69 & & 570 & 439 & 366 & 245 & 149 & 015 & 8,085 \\ & 38 \text { “J" } & & 644 & 466 & 405 & 319 & 150 & 020 & 8,545 \\ 25 \text { anos e } & 19 & & & 472 & 415 & {[444](3)} & {[378](3)[100](3)} & 7,930 \\ \text { mais } & 7 \text { “" } & & & {[609](3)} & {[356](3)} & {[300](3)} & {[100](3)} & 0 & {[-](3)}\end{array}$

\section{Mulheres}

casadas em

1985-1919

\begin{tabular}{|c|c|c|c|c|c|c|c|c|c|}
\hline \multirow[t]{2}{*}{$15-19$ anos } & 84 & 505 & 390 & 238 & 130 & 069 & 030 & 011 & 5,234 \\
\hline & 27 “J” & 677 & 433 & 257 & 106 & 081 & 059 & 0 & 5,495 \\
\hline \multirow{2}{*}{ 20-24 anos } & 120 & & 469 & 353 & 199 & 123 & 050 & 003 & 5,048 \\
\hline & 19 “Ј” & & 568 & 351 & 245 & 099 & 031 & 0 & 5,288 \\
\hline \multirow{2}{*}{$\begin{array}{l}25 \text { anos e } \\
\text { mais }\end{array}$} & 35 & & & 331 & 369 & 217 & 095 & 023 & 4,348 \\
\hline & $7 " \mathrm{~J}$ & & & [448] (3) & [269 (3) & [367] (3) & [194] (3) & [100] (3) & {$[-](3)$} \\
\hline \multicolumn{10}{|l|}{$\begin{array}{l}\text { Mulheres } \\
\text { casadas em } \\
1920-1939\end{array}$} \\
\hline \multirow[t]{2}{*}{$15-19$ anos } & 53 & 341 & 299 & 177 & 53 & 045 & $-(4)$ & $-(4)$ & {$[3,348]$} \\
\hline & 12 “J” & 587 & 356 & 252 & 195 & 0 & $-(4)$ & $-(4)$ & {$[5,190]$} \\
\hline \multirow[t]{2}{*}{ 20-24 anos } & 90 & & 350 & 238 & 104 & 081 & 048 & $-(4)$ & {$[3,429]$} \\
\hline & 13 “Ј” & & 341 & 218 & [266] (3) & [250] (3) & $-(4)$ & $-(4)$ & {$[3,482]$} \\
\hline \multirow{2}{*}{$\begin{array}{l}25 \text { anos e } \\
\text { mais }\end{array}$} & 48 & & & 323 & 279 & 156 & 74 & 0 & 3,391 \\
\hline & 7 “ & & & [125] (3) & [209] (3) & [103] (3) & [212] (3) & $-(4)$ & {$[-](3)$} \\
\hline
\end{tabular}

Fonte Comunidade Evangélica Luterana de Curitiba - Registros Paroquiais.

(1) Por mil mulheres.

(2) Fichas MF.

(3) Efetivos muito pequenos.

(4) Tendo em vista fim de observação determinado em 31/12/1939, dados indisponíveis.

"cultura" fundada na Deutschbrasilianertum (SEYFERT, 1994, p. 19), consagrando um grupo étnico "teuto-brasileiro" distinto ao mesmo tempo dos imigrantes germânicos e dos "brasileiros". Para além dos contatos culturais que envolvem imigrantes e descendentes, a especificidade destes descendentes de imigrantes deriva "da experiência comum da colonização". ${ }^{16}$ Portanto, a segunda e a terceira coortes englobavam teuto-brasileiros que manteriam identificadores culturais dos seus pais e avós imigrantes, seja filiando-se a uma ascendência de sangue, seja mantendo a língua

\footnotetext{
16 “É preciso observar que o termo 'colônia', nesse contexto, não diz respeito apenas ao meio rural ou às legiões de assentamentos de imigrantes alemães, mas também às comunidades (no sentido de comunidades étnicas) que congregam pessoas dessa origem nas cidades maiores, como Porto Alegre, Curitiba ou São Paulo" (SEYFERT, 1994, p. 18).
} 
alemã (mesmo deturpada com a utilização de termos e expressões portugueses), seja, finalmente, congregando-se numa igreja de caráter étnico, tal como a Deutsche Evangelische Gemeinde, em Curitiba. ${ }^{17}$

No contraponto, a vivência no cotidiano de uma cidade de padrões morais "lusobrasileiros" interferiria nos comportamentos dos Deutschbrasilianer em relação à virgindade feminina e ao casamento. Este argumento é fortalecido pela análise de alguns dados que se conhecem para a Europa setentrional. Se, por um lado, é sabido que ocorreu durante o século XIX uma diminuição dos índices gerais de ilegitimidade no seu sentido mais amplo (fenômeno particularmente evidente na Alemanha - sem dúvida efeito da contracepção), por outro, tal fato não foi verificado com as séries relativas à ilegitimidade caracterizada pelas concepções pré-nupciais: entre 1850 e 1930, os dados mostram porcentagens elevadas e suficientemente estáveis (SHORTER, 1973, p. 636-639). Mais ainda, existem indicações de que, durante todo o oitocentos, aumentou a freqüência das concepções anteriores ao casamento (IMHOF, 1975, p. 471).

\section{Uma atitude crítica relacionada à reconstituição de famílias}

Esta sessão do texto endossa particularmente a necessária atitude crítica em relação à metodologia da reconstituição familiar, no que se refere ao problema da possibilidade ou não de se tirarem conclusões a respeito da análise das famílias MF, uma vez que os processos migratórios introduzem uma seleção no estoque das famílias reconstituídas (DUPÂQUIER, 1984, p. 104).$^{18} \mathrm{Em}$ primeiro lugar, tais inferências podem ser maiores ou menores à medida que se considera o chamado "índice de rendimento" da reconstituição (HENRY, 1988, p. 100; NADALIN, 2000, p. 251-2; DUPÂQUIER, 1984, p. 94-9). Outra maneira seria testar uma comparação entre os casais MF e EF - isto é, entre os casais mais ou menos estáveis (Tabela 3) -, com os cuidados necessários para não introduzir vieses (HENRY, 1988, p. 125-128). Estes últimos caracterizam-se por uma relativa mobilidade anterior à fase estável dos seus ciclos matrimoniais, o que auxiliou para se chegar a algumas conclusões. ${ }^{19}$

Pela análise da origem dos cônjuges, verificou-se que, tanto para as famílias MF como para as EF, durante todo o período de 1866 a 1939, sempre foi elevado o número de pessoas nascidas no estrangeiro, ou pelo menos fora de Curitiba. Evidentemente, esta proporção era mais significativa entre as famílias EF, e este fato permite grifar o que até aqui ficou implícito. Ao formular o problema das eventuais diferenças entre as duas categorias de famílias, Henry (1988) fundamentava-se empiricamente em populações européias. No Brasil, ao contrário, tratamos de efetivos instalados em territórios mais vastos, onde as migrações de um local ou de uma paróquia para outra implicavam, em geral, distâncias relativamente longas. Além disso, visualiza-se outra especificidade: além de "imigrarem" de diversas regiões do Brasil Meridional, imigravam também do outro lado do Atlântico.

Enfim, centrando agora o foco nos casais luteranos em Curitiba, muitos haviam começado seus ciclos matrimoniais em outros lugares, que poderiam ser até muito distantes. Isto explica por que as mulheres das famílias mais "móveis" (EF), no início das suas histórias conjugais na comunidade, também foram identificadas por

\footnotetext{
${ }^{17}$ O luteranismo no Brasil organiza-se em dois grandes grupos: a “Igreja Evangélica de Confissão Luterana no Brasil” (IECLB), herdeira de uma Federação Sinodal, congregando as diversas paróquias submetidas ao luteranismo alemão, ea "Igreja Evangélica Luterana do Brasil" (IELB), ligada ao Sínodo do Missouri (portanto, a missionários teuto-norte-americanos), que sempre "postulou sua religiosidade como necessariamente transétnica e, portanto, não restrita à etnia alemã" (JUNGBLUT, 1994, p. 142). De um modo ou de outro, as informações que temos é de que atualmente as duas igrejas - IECLB e IELB - compõem-se de cerca de $90 \%$ de adeptos de origem imigrante alemã (idem, p. 144).

${ }^{18} \mathrm{O}$ fato é denunciado por muitos. Othero (1998, p. 450-455), por exemplo, faz uma série de considerações a respeito, discutindo limites e virtualidades. Da mesma forma, Reher (1197, p. 102), que resume a questão a respeito da representatividade das fichas de família.

${ }^{19}$ Ver a íntegra deste trabalho em Bideau e Nadalin (1992, p. 163-175).
} 
TABELA 3

Taxas corrigidas e comparadas de fecundidade (1), por grupos de idade da mãe, segundo idade da mulher no início da observação (2)

Comunidade Evangélica Luterana de Curitiba-1866-1939

\begin{tabular}{|c|c|c|c|c|c|c|c|c|c|c|c|}
\hline \multirow{2}{*}{$\begin{array}{l}\text { Idade da } \\
\text { mulher no } \\
\text { início da } \\
\text { obs. }\end{array}$} & \multirow{2}{*}{$\begin{array}{l}N^{\circ} \text { de } \\
\text { fichas } \\
\text { de } \\
\text { família }\end{array}$} & \multirow{2}{*}{$\begin{array}{l}\text { Categ. } \\
\text { Fichas } \\
\text { de } \\
\text { família }\end{array}$} & \multirow{2}{*}{$\begin{array}{c}\text { Relação } \\
\text { EF/M }{ }^{e} F \\
(\%)\end{array}$} & \multicolumn{7}{|c|}{ Idade observada da mulher } & \multirow{2}{*}{$\begin{array}{l}\text { Descen- } \\
\text { dência } \\
\text { completa }\end{array}$} \\
\hline & & & & $\begin{array}{l}15-19 \\
\text { anos }\end{array}$ & $\begin{array}{c}20-24 \\
\text { anos }\end{array}$ & $\begin{array}{c}25-29 \\
\text { anos }\end{array}$ & $\begin{array}{l}30-34 \\
\text { anos }\end{array}$ & $\begin{array}{l}\text { 35-39 } \\
\text { anos }\end{array}$ & $\begin{array}{l}40-44 \\
\text { anos }\end{array}$ & $\begin{array}{l}45-49 \\
\text { anos }\end{array}$ & \\
\hline \multicolumn{12}{|l|}{$\begin{array}{l}\text { Início de } \\
\text { observação } \\
\text { em 1866-1894 }\end{array}$} \\
\hline \multirow[t]{2}{*}{ 15-19 anos } & 9 & EF & \multirow{2}{*}{14,8} & 343 & 377 & 333 & 234 & 098 & 033 & 0 & 6,980 \\
\hline & 61 & $M^{e} F(3)$ & & 309 & 408 & 381 & 312 & 203 & 082 & 005 & 6,894 \\
\hline \multirow[t]{2}{*}{ 20-24 anos } & 16 & EF & \multirow{2}{*}{12,6} & & 240 & 471 & 399 & 247 & 180 & 024 & 5,082 \\
\hline & 127 & $M^{e} F(3)$ & & & 399 & 359 & 342 & 82 & 130 & 016 & 4,933 \\
\hline \multirow[t]{2}{*}{ 25-29 anos } & 28 & $\mathrm{EF}$ & \multirow{2}{*}{127,3} & & & 305 & 356 & 317 & 143 & 19 & (4) \\
\hline & 22 & $M^{e} F(3)$ & & & & 400 & 435 & 213 & 095 & 0 & (4) \\
\hline \multirow[t]{2}{*}{30 anos e mais } & s 43 & EF & \multirow[b]{2}{*}{330,8} & & & & 320 & 301 & 207 & 29 & (4) \\
\hline & 13 & $M^{e} F(3)$ & & & & & $316(4)$ & $333(4)$ & $200(4)$ & $036(4)$ & (4) \\
\hline \multicolumn{12}{|l|}{$\begin{array}{l}\text { Início de } \\
\text { observaçãa } \\
\text { em 1895-1919 }\end{array}$} \\
\hline \multirow[t]{2}{*}{$15-19$ anos } & 32 & EF & \multirow{2}{*}{44,4} & 222 & 318 & 235 & 105 & 078 & 028 & 025 & 4,320 \\
\hline & 72 & $M^{e} F(3)$ & & 191 & 259 & 261 & 127 & 069 & 025 & 011 & 4,494 \\
\hline \multirow[t]{2}{*}{ 20-24 anos } & 79 & $\mathrm{EF}$ & \multirow{2}{*}{54,9} & & 274 & 332 & 187 & 124 & 088 & 009 & 4,353 \\
\hline & 144 & $M^{e} F(3)$ & & & 315 & 311 & 182 & 111 & 047 & 0 & 4,083 \\
\hline \multirow[t]{2}{*}{ 25-29 anos } & 31 & $\mathrm{EF}$ & \multirow{2}{*}{72,9} & & & 343 & 328 & 132 & 059 & 0 & 3,463 \\
\hline & 43 & $M^{e} F(3)$ & & & & 254 & 283 & 135 & 074 & 014 & 3,365 \\
\hline \multirow[t]{2}{*}{30 anos e mais } & s 39 & $\mathrm{EF}$ & \multirow{2}{*}{185,7} & & & & 234 & 218 & 093 & 017 & (4) \\
\hline & 21 & $M^{e} F(3)$ & & & & & 204 & 299 & 098 & $040(4)$ & (4) \\
\hline \multicolumn{12}{|l|}{$\begin{array}{l}\text { Início de } \\
\text { observação } \\
\text { em 1920-1939 }\end{array}$} \\
\hline \multirow[t]{2}{*}{ 15-19 anos } & 14 & EF & \multirow{2}{*}{48,3} & 182 & 257 & 123 & 114 & 0 & (5) & (5) & (5) \\
\hline & 29 & $M^{e} F(3)$ & & 338 & 264 & 221 & 050 & 0 & (5) & (5) & (5) \\
\hline \multirow[t]{2}{*}{ 20-24 anos } & 48 & EF & \multirow{2}{*}{46,2} & & 204 & 220 & 106 & 047 & 0 & (5) & (5) \\
\hline & 104 & $\mathrm{M}^{e} \mathrm{~F}(3)$ & & & 168 & 213 & 084 & 064 & $95(4)$ & (5) & (5) \\
\hline 25-29 anos & 30 & $\mathrm{EF}$ & & & & 174 & 187 & 047 & 037 & (5) & (5) \\
\hline & 25 & $M^{e} F(3)$ & 120,0 & & & 149 & 201 & 090 & 0 & (5) & (5) \\
\hline 30 anos e mais & s 39 & $\mathrm{EF}$ & & & & & 200 & 154 & 044 & 0 & (4) \\
\hline & 23 & $M^{e} F(3)$ & 169,6 & & & & 234 & 145 & 081 & 0 & (4) \\
\hline
\end{tabular}

Fonte: Comunidade Evangélica Luterana de Curitiba - Registros Paroquiais

(1) Por mil mulheres.

(2) Fichas $E F / M^{e} F$ (famílias móveis e famílias estáveis).

(3) $\mathrm{M}^{\mathrm{e}} \mathrm{F}$ - Fichas abertas em função do matrimônio, mas cujo início de observação é determinado pelo nascimento do primeiro filho.

(4) Efetivos muito pequenos.

(5) Tendo em vista fim de observação determinado em 31/12/1939, dados indisponíveis.

serem em média mais velhas do que as casadas na paróquia. Observa-se que esta tendência é geral, válida para todas as coortes estudadas, mesmo para o segundo subgrupo de casais EF que, por hipótese, teria sido formado por indivíduos que se escolheram em função das ofertas de um mercado matrimonial regional (Tabela 3).
As análises realizadas permitiram colocar em evidência uma provável fecundidade mais forte das famílias instáveis, o que incita a formulação de novas questões. Se isso realmente for verdade, como explicar-se-ia esta maior vitalidade das mulheres EF? Por que as famílias móveis tenderiam a ter mais filhos do que as 
sedentárias? Seria talvez por que, forçadas a interromper a sucessão normal de gestações por causa das migrações, estas famílias, ao se estabelecerem de novo, retomaram com mais vigor seus ciclos fecundos, como uma espécie de compensação pela instabilidade anterior? As questões se sucedem e instigam perguntas principalmente enfocadas nos imigrantes europeus, imaginando-se que possam ter contribuído substancialmente no caráter diferencial desses casais. Assim, seria este revigoramento relacionado à fecundidade fundamentado nas esperanças e angústias relativas à nova vida que teriam de empreender no país de adoção? Ou, numa outra perspectiva, teria este fato a ver com uma provável seleção natural resultante do processo migratório?

É necessário lembrar que, se a miséria expulsou o camponês do campo, ou o artesão da cidade, se a revolução abortada e alguns ideais políticos motivaram emigrações, ${ }^{20}$ tais fatores de deslocamentos populacionais não alcançaram todos os indivíduos que constituíam a sociedade emissora.

De um modo ou de outro, as questões evidenciadas fortalecem a necessidade de cuidados ao extrapolar para o conjunto de toda a sociedade o comportamento demográfico das famílias mais estáveis, do tipo MF.

Chamou-se a atenção, anteriormente, sobre algumas pesquisas realizadas num passado recente. Sua base foi constituída por fichas de família que, completadas até $1987,{ }^{21}$ somam 10.356 , de todo tipo (MF, MO, EF e EO), ${ }^{22}$ contendo informações mais ou menos completas a respeito de 34.590 indivíduos que, durante mais de um século, viveram, amaram e morreram em Curitiba, ou simplesmente "passaram" pelos registros paroquiais, nascendo e depois desaparecendo da observação, ou mencionados como pais dos noivos - estando ou não presentes na cerimônia do casamento. Essas fichas testemunham uma atividade que praticamente começou em 1974, com a sua "abertura" durante exercício prático no curso ministrado por Louis Henry, na Universidade Federal do Paraná. Ainda hoje têm sido utilizadas como base de anotações diversas, relacionadas aos indivíduos concernentes, e obtidas de fontes variadas: algumas de cunho administrativo (informações encontradas nos arquivos da comunidade); outras, de natureza oficial ou não, fornecendo dados a respeito de atividades profissionais dos membros da comunidade religiosa. Nesse sentido, são seguidas aquelas clássicas recomendações, de anotar nas fichas de família todas as informações dispersas em documentos de características diversas (DUPÂQUIER, 1977, p. 311).

Tudo isso colocado em evidência explica, portanto, o engajamento favorável em relação a todas as possibilidades atinentes à base de dados permitidas pela metodologia, principalmente quando se pode associar informações de caráter demográfico com dados biográficos e genealógicos, no amplo espectro de uma História Social.

Independentemente da importância historiográfica da metodologia, suas virtualidades também se destacam desde que os seus limites sejam conhecidos. No caso do presente estudo, depois de comentar as diversas questões relacionadas à metodologia, Fleury e Henry ressalvam que, em boa medida, a reconstituição das famílias evangélico-luteranas em Curitiba escapa aos problemas esboçados, ${ }^{23}$ pois o

\footnotetext{
${ }^{20}$ Ver em Willems (1980, p.32-7) uma boa análise das causas da emigração alemã.

${ }^{21}$ Os procedimentos relacionados à reconstituição de famílias encerraram-se neste ano, aproveitando as informações coletadas por ocasião de um censo nacional organizado pela Igreja Evangélica Luterana do Brasil. Foram consultados os boletins do recenseamento relacionados aos luteranos que vivem em Curitiba: apesar de apresentarem problemas, as informações possíveis foram aproveitadas para o encerramento das observações, em 30 de junho de 1987.

${ }^{22}$ Completando informações anteriores, as fichas $\mathrm{MO}$ e EO caracterizam-se pela existência de uma data de início de observação, mas não foi possível determinar empiricamente uma data de final de observação, resultando na informação "O", de "ouvert", aberto.

${ }^{23}$ De fato, o texto em destaque refere-se igualmente ao trabalho de Maria Luiza Andreazza (1999), da mesma forma fundado na metodologia, que se dedicou em sua tese de doutorado a um grupo de origem ucraniana instalado numa colônia agrícola no Paraná.
} 
pertencimento dos imigrantes e dos teutobrasileiros ao culto luterano permite

identificar y aislar más fácilmente a los miembros de cada grupo en el conjunto poblacional en el que se insertan, al tiempo que los relativamente bajos niveles de ilegimidad observados contribuyen a paliar el problema de los rendimentos. La indagación sabiamente orientada hacia las pautas reproductivas optimiza las potencialidades del método y permite reducir los riesgos evocados. Ahora bien, ¿que sucede cuando el investigador de las migraciones se orienta de preferencia al estudio de grupos no minoritarios o bien instalados en áreas urbanas com mayor población? En igual sentido, ¿cual es la utilidade de la reconstitución de familias cuando las indagaciones se extienden más allá del problema, ciertamente específico, de la fecundidad diferencial para incorporar la entera vida social de los migrantes? De modo análogo a lo ocurrido con el concepto de corresidencia del clásico modelo Laslett de estudio de la familia, se impone aquí una ampliación de las perspectivas que supere el problema de la unidad de análisis artificialmente aislada del contexto social en que se inserta. Las opciones metodológicas para tal superación son bien conocidas: genealogías, prosopografías, redes sociales, etc. ${ }^{[\cdots]}$, estrategias de indagación que testimonian una ampliación técnica pero también heurística y, muy especialmente, conceptual (OTHERO, 1998, p. 453).

\section{Nominação e identidade étnica}

Assim, diante da dupla possibilidade colocada pelos procedimentos da reconstituição de família - os recortes longitudinais permitidos pelas análises das diversas coortes antes mencionadas e a ênfase nas linhagens genealógicas contidas na base de dados, recuperadas convenientemente pelo software SYGAP - e tendo como horizonte os estudos relativos à fecundidade já realizados, ressalta-se o resultado positivo de um primeiro ensaio metodológico desenvolvido sobre a nominação por ocasião do Batismo, enfoque e abordagem que levam às possíveis motivações dos pais (e da própria família) ao escolherem o nome das crianças, levando ao estudo do compadrio (NADALIN; BIDEAU, 2004; 2005).

As questões foram desenvolvidas observando-se de que maneira os descendentes de um imigrante, Augusto Strobel, batizaram seus filhos, identificando-os por meio de um prenome. Ignorando-se as variadas combinações possíveis, em cada geração tais escolhas foram identificadas em função de três categorias ${ }^{24}$ relacionadas às fronteiras étnicas nas quais estes descendentes se inseriam, uma vez que faziam parte da Igreja Evangélica Alemã em Curitiba (Tabela 4).

TABELA 4

A linhagem Strobel - Escolha dos prenomes de Batismo, por categorias, segundo gerações Comunidade Evangélica Luterana de Curitiba - séculos XIX-XX

\begin{tabular}{|c|c|c|c|c|c|c|c|c|}
\hline \multirow{3}{*}{ Gerações } & \multicolumn{8}{|c|}{ Categorias (1) } \\
\hline & \multicolumn{2}{|l|}{ I } & \multicolumn{2}{|l|}{ II } & \multicolumn{2}{|l|}{ III } & \multicolumn{2}{|l|}{ Total } \\
\hline & №s absolutos & $\%$ & №s absolutos & $\%$ & $\mathrm{~N}^{\mathrm{os}}$ absolutos & $\%$ & №s absolutos & $\%$ \\
\hline $1^{\underline{a}}$ & 3 & 50,0 & 3 & 50,0 & - & - & 6 & 100,0 \\
\hline $2^{\mathrm{a}}$ & 28 & 78,0 & 7 & 19,0 & 1 & 3,0 & 36 & 100,0 \\
\hline $3^{\mathrm{a}}$ & 28 & 47,0 & 23 & 39,0 & 8 & 14,0 & 59 & 100,0 \\
\hline $4^{\mathrm{a}}$ & 3 & 6,0 & 15 & 28,0 & 36 & 66,0 & 54 & 100,0 \\
\hline $5^{\mathrm{a}}$ & - & - & 5 & 23,0 & 17 & 77,0 & 22 & 100,0 \\
\hline Total & 62 & 35,0 & 53 & 30,0 & 62 & 35,0 & 177 & 100,0 \\
\hline
\end{tabular}

Fonte: Comunidade Evangélica Luterana de Curitiba - Registros Paroquiais. SYGAP - indiv.dbf.

(1) Categorias:

I - August, Karl, Erwin, Franz, Gottlieb, Heinrich, Johann, Ludwig, Otto, Richard, Theodor, Wilhelm e outros. Adelheid, Bertha. Katharine, Ernestine, Frieda, Hedwig, Ida, Johanne, Louise, Mathilde, Rose, Sophie, Wilhelmine e outros.

II - Carlos, Francisco, Jorge, Günther, Henrique, João, Manfred, Lotário, Rolf, Siegfried, Waldemar e outros. Adelaide, Berta, Karin, Dagmar, Edeltraut, Frida, Guiomar, Hedy, Ilsa, Julia, Margit, Rosalina, Teresa, Ursula, Wanda e outros.

III - Augusto, Alberto, Antonio, Arnaldo, Eduardo, Fernando, Gustavo, Heraldo, Júlio, Ricardo, Roberto, Ronaldo e outros. Inês, Ana, Alberta, Amélia, Carina, Cristina, Isabel, Ilda, Judite, Lúcia, Margarete, Paula, Renata e outros.

\footnotetext{
${ }^{24}$ Categoria I: nomes oriundos do estoque imigrante original; categoria II: nomes característicos do estoque "teuto-brasileiro"; categoria III: nomes diversos, de estoques da "moda". Simplificando bastante, escolher um nome da primeira categoria mostraria um casal com tendências a traduzir uma cultura imigrante, enquanto a categoria II reflete uma resposta "teuto-brasileira", ao processo dos contatos culturais. Finalmente, a escolha de um prenome característico da categoria III (inclui todos os nomes não listados nas duas primeiras categorias) envolve um sintoma de assimilação.
} 
Tendo em vista as possibilidades demonstradas acima, os dados foram agre- gados por coortes (Tabela 5) e, em seguida, pela ordenação dos nascimentos (sempre

TABELA 5

Escolha dos prenomes de Batismo, por categorias, segundo coortes Comunidade Evangélica Luterana de Curitiba - 1866-1964

\begin{tabular}{|c|c|c|c|c|c|c|c|c|}
\hline \multirow{3}{*}{ Coortes } & \multicolumn{8}{|c|}{ Categorias (1) } \\
\hline & \multicolumn{2}{|l|}{ I } & \multicolumn{2}{|l|}{ II } & \multicolumn{2}{|l|}{ III } & \multicolumn{2}{|c|}{ Total } \\
\hline & $\begin{array}{c}\text { Nos } \\
\text { absolutos }\end{array}$ & $\%$ & $\begin{array}{c}\mathrm{N}{ }^{\text {os }} \\
\text { absolutos }\end{array}$ & $\%$ & $\begin{array}{c}N^{\text {os }} \\
\text { absolutos }\end{array}$ & $\%$ & $\begin{array}{c}\text { Nos } \\
\text { absolutos }\end{array}$ & $\%$ \\
\hline $1866-1894$ & 313 & 72,0 & 93 & 21,4 & 29 & 6,7 & 435 & 100,0 \\
\hline $1895-1919$ & 229 & 43,9 & 154 & 29,5 & 139 & 26,6 & 522 & 100,0 \\
\hline $1920-1939$ & 93 & 15,3 & 188 & 31,0 & 325 & 53,6 & 606 & 100,0 \\
\hline $1940-1964$ & 51 & 6,6 & 157 & 20,3 & 566 & 73,1 & 774 & 100,0 \\
\hline $\begin{array}{l}\text { Total das } \\
\text { coortes } \\
1866-1964\end{array}$ & 686 & 29,4 & 592 & 25,3 & 1.059 & 45,3 & 2.337 & 100,0 \\
\hline
\end{tabular}

Fonte: Comunidade Evangélica Luterana de Curitiba - Registros Paroquiais. Fichas de Família MF.

(1) Categorias:

I - August, Karl, Erwin, Franz, Gottlieb, Heinrich, Johann, Ludwig, Otto, Richard, Theodor, Wilhelm e outros. Adelheid, Bertha. Katharine, Ernestine, Frieda, Hedwig, Ida, Johanne, Louise, Mathilde, Rose, Sophie, Wilhelmine e outros.

II - Carlos, Francisco, Jorge, Günther, Henrique, João, Manfred, Lotário, Rolf, Siegfried, Waldemar e outros. Adelaide, Berta, Karin, Dagmar, Edeltraut, Frida, Guiomar, Hedy, Ilsa, Julia, Margit, Rosalina, Teresa, Ursula, Wanda e outros.

III - Augusto, Alberto, Antonio, Arnaldo, Eduardo, Fernando, Gustavo, Heraldo, Júlio, Ricardo, Roberto, Ronaldo e outros. Inês, Ana, Alberta, Amélia, Carina, Cristina, Isabel, Ilda, Judite, Lúcia, Margarete, Paula, Renata e outros.

TABELA 6

Escolha dos prenomes de Batismo de primogênitos e ultimogênitos, por categorias, segundo coortes

Comunidade Evangélica Luterana de Curitiba - 1866-1964

\begin{tabular}{|c|c|c|c|c|c|c|c|c|c|}
\hline \multirow{3}{*}{ Coortes } & \multirow{3}{*}{$\begin{array}{c}\text { Ordem do } \\
\text { nascimento }\end{array}$} & \multicolumn{8}{|c|}{ Categorias(1) } \\
\hline & & \multicolumn{2}{|l|}{$\mathbf{I}$} & \multicolumn{2}{|l|}{ II } & \multicolumn{2}{|l|}{ III } & \multicolumn{2}{|l|}{ Total } \\
\hline & & $\begin{array}{c}\text { №s } \\
\text { absolutos }\end{array}$ & $\%$ & $\begin{array}{c}N^{\text {Nos }} \\
\text { absolutos }\end{array}$ & $\%$ & $\begin{array}{c}\text { №s } \\
\text { absolutos }\end{array}$ & $\%$ & $\begin{array}{c}\text { №s } \\
\text { absolutos }\end{array}$ & $\%$ \\
\hline \multirow{2}{*}{ I } & Primogênito & 175 & 77,8 & 42 & 18,7 & 8 & 3,5 & 225 & 100,0 \\
\hline & diferença & - & 12,1 & - & $-5,6$ & - & $-6,5$ & - & - \\
\hline $1866-1894$ & Ultimogênito & 138 & 65,7 & 51 & 24,3 & 21 & 10,0 & 210 & 100,0 \\
\hline & Primogênito & 144 & 52,5 & 81 & 29,6 & 49 & 17,9 & 274 & 100,0 \\
\hline & diferença & - & 18,0 & - & 0,3 & - & 18,3 & - & - \\
\hline $1895-1919$ & Ultimogênito & 85 & 34,5 & 73 & 29,3 & 90 & 36,2 & 248 & 100,0 \\
\hline \multirow{2}{*}{ III } & Primogênito & 61 & 18,0 & 101 & 29,8 & 177 & 52,2 & 339 & 100,0 \\
\hline & diferença & - & 6,0 & - & $-2,8$ & - & $-3,2$ & - & - \\
\hline $1920-1939$ & Ultimogênito & 32 & 12,0 & 87 & 32,6 & 148 & 55,4 & 267 & 100,0 \\
\hline \multirow{3}{*}{$\begin{array}{c}\text { IV } \\
1940-1964\end{array}$} & Primogênito & 38 & 9,0 & 92 & 21,9 & 291 & 69,1 & 421 & 100,0 \\
\hline & diferença & - & 5,3 & - & 2,5 & - & 8,8 & - & - \\
\hline & Ultimogênito & 13 & 3,7 & 65 & 18,4 & 275 & 77,9 & 353 & 100,0 \\
\hline
\end{tabular}

Fonte: Comunidade Evangélica Luterana de Curitiba - Registros Paroquiais. Fichas de Família MF.

(1) Categorias:

I - August, Karl, Erwin, Franz, Gottlieb, Heinrich, Johann, Ludwig, Otto, Richard, Theodor, Wilhelm e outros. Adelheid, Bertha. Katharine, Ernestine, Frieda, Hedwig, Ida, Johanne, Louise, Mathilde, Rose, Sophie, Wilhelmine e outros.

II - Carlos, Francisco, Jorge, Günther, Henrique, João, Manfred, Lotário, Rolf, Siegfried, Waldemar e outros. Adelaide, Berta, Karin, Dagmar, Edeltraut, Frida, Guiomar, Hedy, Ilsa, Julia, Margit, Rosalina, Teresa, Ursula, Wanda e outros.

III - Augusto, Alberto, Antonio, Arnaldo, Eduardo, Fernando, Gustavo, Heraldo, Júlio, Ricardo, Roberto, Ronaldo e outros. Inês, Ana, Alberta, Amélia, Carina, Cristina, Isabel, Ilda, Judite, Lúcia, Margarete, Paula, Renata e outros. 
com a finalidade de se observarem as influências étnicas nos diversos períodos da história da comunidade e no interior da história da família), arranjados para estudar os comportamentos diferenciados na nominação dos primeiros e últimos filhos (Tabela 6).

Por falta de espaço, é impossível que se refaça, neste texto, uma análise um pouco mais adequada das Tabelas 4 a 6 , já realizada em outro lugar (NADALIN; BIDEAU, 2004, 2005). No entanto, de certa forma, seus números "falam por si", mostrando como, durante a história da comunidade, os membros do grupo alteraram parcialmente seus comportamentos, numa direção "assimilacionista". Também deve-se salientar que, ao tipo de análise já realizada, serão agregadas aquelas fundadas em dados obtidos de fichas EF, numa tentativa de comparação.

\section{Conclusão}

Mas a pesquisa não pretende parar nesse tipo de abordagem. A partir de uma problemática mais clássica a respeito da nominação, ao acervo de fichas de família, serão adicionados convenientemente complementos, arrolando-se o nome dos testemunhos de casamento e dos padrinhos das crianças (sempre em função da ordem dos nascimentos) e, ao mesmo tempo, agregados os casais unidos em matrimônio na Igreja Católica e seus filhos. ${ }^{25}$ Tal démarche permitirá o encaminhamento da investigação, tendo como fio condutor as perguntas atinentes às relações dos pais com os avós (e, por ricochete, questões referentes à mortalidade); eventualmente,

\section{Referências bibliográficas}

BARTH, F. Grupos étnicos e suas fronteiras. In: POUTIGNAT, P.; STREIFF-FENART, J. Teorias da etnicidade. Seguido de grupos étnicos e suas fronteiras de Fredrik Barth. São Paulo: Fundação Editora da Unesp, 1998, p. 185-227. também, relações com outros parentes e com os indivíduos - membros do grupo étnico e/ou da comunidade, ou não - escoIhidos como padrinhos e madrinhas. Quem sabe, poder-se-á, então, conduzir a problemática da pesquisa a respeito da comunidade dos imigrantes e descendentes em Curitiba na direção de algumas linhagens familiares e na orientação lembrada por Hernan Othero (1998), de uma abordagem mais ampla, tais como aquelas propiciadas pelo estudo de redes de família.

A reconstituição de famílias da Comunidade Evangélica Luterana de Curitiba resultou de um trabalho longo e árduo, mas que, apesar de tudo, deu muito prazer. É evidente que isso foi permitido pela consideração dos colegas do Departamento de História da UFPR que, em vários momentos, aprovaram os sucessivos projetos de pesquisa, construídos para dar conta da dinâmica da problemática dos contatos culturais entre os imigrantes de origem e descendentes na capital paranaense. De forma igual, pelos colegas historiadores que, ao constituírem desde 1975 os diversos Comitês Assessores da Área de História e de Demografia no Conselho Nacional de Desenvolvimento Científico e Tecnológico (CNPq), homologaram os pareceres dos consultores ad hoc que encaminharam favoravelmente os pedidos de bolsa de pesquisa. Portanto, a tonalidade dada ao texto não envolve arrependimentos, mesmo tendo consciência dos limites epistemológicos relacionados ao conceito de família implicitado e do alcance também limitado dos estudos demográficos oriundos da base de dados obtida da metodologia.

BIDEAU, A. et al. SYGAP. Système de gestion et d'analyse de population. Villeurbanne: Programme Pluriannuel en Sciences Humaines Rhone-Alpes, 1991.

BIDEAU, A.; NADALIN, S.O. Étude de la fécondité d'une commun auté évangélique

\footnotetext{
${ }^{25}$ Serlei Maria Fischer Ranzi (1996) fez a reconstituição de famílias católicas de origem germânica, para o período 1850-1919.
} 
luthérienne à Curitiba (Brésil) de 1866 à 1939. Population, n.6, p.1035-1064, 1988.

Histórias de vida e análise demográfica da fecundidade: abordagens complementares para uma história de comportamento social. In: NADALIN, S.O.; MARCÍLIO, M.L.; BALHANA, A.P. (Orgs.). História e população: estudos sobre a América Latina. São Paulo, Fundação Sistema Estadual de Análise de Dados, 1990, p. 131-141 (O mesmo texto foi publicado como BIDEAU, A.; NADALIN, S. O. Histoires de vie et analyse démographique de la fécondité: approches complémentaires pour une histoire du comportement social. L'exemple de la Communauté Évangélique Luthérienne de Curitiba (1866-1939). Annalise de Démographie Historique. Paris: SDH/ EHESS, 1991, p. 157-171).

. Familles stables et familles móbiles. une nouvelle approche de la fécondité différentielle. L'exemple de la communauté évangélique luthérienne de Curitiba entre 1866 et 1939. El poblamiento de las Américas; Actas Veracruz, lussp, v.2, p. 163175, 1992.

Comment des luthériens allemands sont-ils devenus des brésiliens? Un essai méthodologique. In: BRUNET; G.; ORIS, M.; BIDEAU, A. (Éds.). Les minorities Minorities. Une démographie culturelle et politique, XVIIIe-XX siècles - A Cultural and Political Demography, $18^{\text {th }}-20^{\text {th }}$ Centuries. Berna: Peter Lang, 2004. (O texto foi publicado em inglês: BIDEAU, A.; NADALIN, S.O. How german lutherans became brazilians: a methodological essay. The History of the Family, An International Quarterly, v.10, n.1, 2005. Em português, o texto pode ser acessado em http://www.brnuede.com/bhds/ bhd29/nadalin.pdf ).

DREHER, M. Igreja e germanidade; estudo crítico da história da Igreja Evangélica de Confissão Luterana no Brasil. São Leopoldo: Editora Sinodal, 1984.

DUPÂQUIER, J. Histoire et Démographie. Population, v.32 (numéro spécial), p. 299321, 1977.

Paris: PUF, 1984.
FLEURY, M.; HENRY, L. Nouveau manuel de dépouillement et d'exploitation de l'état civil ancién. Paris: Ined, 1965.

GAUTIER, É.; HENRY, L. La population de Crulai, paroisse normande; étude historique. Paris: Ined/PUF, 1958.

GOUBERT, P. Beauvais et lê Beauvaisis de 1600 à 1730. Contribution à l'histoire sociale de la France au dix-septième siècle. Paris: Sevpen, 1960.

HENRY, L. Anciennes familles genevoises, etude démographique: seizième-vingtième siècles. Paris: Ined/PUF, 1956.

Técnicas de análise em demografia histórica. Lisboa: Gradiva, 1988.

IMHOF, A. E. Die namentliche Auswertung der Kirchenbücher. Die Familien von Giessen 1631-1730 und Heuchelheim 1691-1900. In: (Org.). Historische Demographie als Sozialgeschichte: Giessen un Umgebung vom 17. zum 19. Jahrhundert (v.1). Darmstadt/Marburg: Symon un Wagner KG,p. 279-516, 1975.

JUNGBLUT, A. L. O protestantismo luterano dos teuto-brasileiros: algumas considerações necessárias para uma abordagem antropológica. In: MAUCH, C.; VASCONCELLOS, N. Os alemães no sul do Brasil. Canoas: Ed. Ulbra, 1994, p. 139-147.

NADALIN, S. O. Une paroisse d'origine germanique au Brésil: la Communauté Évangelique Lutheriénne à Curitiba entre 1866 et 1969. Paris, Thèse, Doctorat $3^{\circ}$ Cycle, EHESS, 1978.

. Comportamentos demográficos numa paróquia de origem germânica em Curitiba-Séculos XIX e XX. In: ALBORNOZ, N. S.; CELTON, D.; MIRÓ, C. (Orgs.). Câmbios demográficos en América Latina: la experiencia de cinco siglos. Córdoba (Argentina): Universidad Nacional de Cordoba; Liège: lussp, 1998, p. 461-82.

. Sexuality, marriage, and reproduction. Brazilian Journal of Population Studies, v.1, p. 207-228, 1997/ 1998. [Este artigo foi anteriormente 
publicado em português:

Sexualidade, casamento e reprodução. Revista Brasileira de Estudos de Populacão, v. 5, n. 2, p. 64-94, 1988].

. Imigrantes de origem germânica

no Brasil: ciclos matrimoniais e etnicidade. Curitiba: Aos Quatro Ventos, 2000.

História e Demografia; elementos para um diálogo. Campinas: Associação Brasileira de Estudos Populacionais - Abep, 2004.

OTHERO, H. Continuidad y ruptura em los comportamientos demográficos de los inmigrantes europeus. Enfoques demográficos e históricos. In: ALBORNOZ, N. S.; CELTON, D.; MIRÓ, C. (Orgs.). Câmbios demográficos en América Latina: la experiencia de cinco siglos. Córdoba (Argentina): Universidad Nacional de Cordoba; Liège: lussp, 1998, p. 443-459.

PICHAT, J.-B. Les facteurs de la fecondité non dirigée. Populacion, n.3, p. 383-424, 1965.

RANZI, S. M. F. Alemães católicos, um estudo comparativo de famílias em Curitiba (1850-1919). Tese de doutorado. Curitiba, Universidade Federal do Paraná, 1996.
REHER, D. S. Desafios e conquistas da demografia histórica no final do século. Revista Brasileira de Estudos de População, v.14, n. 1-2, 1997.

SEYFERT, G. Nacionalismo e identidade étnica: a ideologia germanista e o grupo étnico teuto-brasileiro numa comunidade do Vale do Itajaí. Florianópolis: Fundação Catarinense de Cultura, 1981.

. A identidade teuto-brasileira numa perspectiva histórica. In: $\mathrm{MAUCH}, \mathrm{C}$.; VASCONCELLOS, N. Os alemães no sul do Brasil. Canoas: Ed. Ulbra, 1994, p. 11-40.

STONE, L. Família, sexo y matrimonio en Inglaterra; 1500-1800. México: Fondo de Cultura Econômica, 1989.

THERNBORN, G. Sexo e poder; a família no mundo, 1900-2000. São Paulo: Contexto, 2006.

WACHTEL, N. A aculturação. In: LE GOFF, J.; NORA, P. História: novos problemas. 3. ed. Rio de Janeiro: F. Alves, 1988, p. 113-129.

WILLEMS, E. A aculturação dos alemães no Brasil. Estudo antropológico dos imigrantes alemães e seus descendentes no Brasil. 2. ed. São Paulo: Ed. Nacional; [Brasília]: INL, 1980.

\section{Resumen}

Reconstituir familias y demarcar diferencias: virtualidades de la metodología para el estudio de grupos étnicos

Este artículo pretende revisitar algunos textos concernientes a un grupo de inmigrantes de origen germánico y sus descendientes en Curitiba (Paraná), marcando las virtualidades de la metodología de las reconstituciones familiares. Su contenido considera una necesaria actitud crítica que pautó el desarrollo de esos trabajos, teniendo en consideración principalmente, las limitaciones de la metodología y de las propias fuentes "parroquiales". Los primeros resultados se centraran en estudios de fecundidad de tres cohortes de casamientos (18661939) y, en la continuidad, se desarrollaron esfuerzos en el sentido de explorar la base de datos con objetivos que extrapolaron la demografía histórica stricto sensu. El cuadro teórico de la investigación está basado en una historia de la construcción de fronteras étnicas, teniendo como horizonte la inmigración europea, la urbanización, aspectos político-ideológicos y la historia de una institución religiosa.

Palabras-clave: Reconstitución de familias. Inmigración germánica. Contactos culturales. Fronteras étnicas y etnicidad. 


\begin{abstract}
Reconstituting families and determining differences: the potentialities of this methodology for the study of ethnic groups

This article re-examines texts about a group of immigrants of Germanic origin and their descendants in the city of Curitiba, State of Paraná, Brazil, and indicates potentialities of the family reconstitution methodology. In such methodology, the development of this type of research is placed under critical scrutiny, especially as regards to its limitations and the "parochial" sources themselves. The first results were focused on the fecundity studies of three marriage cohorts (1866-1939). Later, efforts were made to explore the database whose objectives had surpassed strictly historical demography. The theoretical framework of the research is based on a history of the construction of ethnic frontiers of European immigration to Brazil, urbanization, politico-ideological questions and the history of a religious institution.
\end{abstract}

Key words: Family reconstitution. German Immigration. Cultural contacts

Recebido para publicação em 22/02/2007. Aceito para publicação em 31/05/2007. 